\title{
环糊精-口卟啉超分子体系的构筑及应用进展
}

\author{
陈韶云周贤太纪红兵* \\ (中山大学化学与化学工程学院 广州 510275)
}

\begin{abstract}
摘要 环糊精具有分子识别和选择包结客体分子的独特性质, 而卟啉具有模拟酶催化、电子转移和光能转移等功能, 本工作通过对环糊精一卟啉超分子体系构筑方式的介绍，详细综述了环糊精一卟啉超分子体系在模拟酶催化、生命科学、 药物控释、电子转移过程等方面的应用, 认为环糊精一卟啉超分子体系具有卟啉和环糊精双重性质的优点, 而以键联环 糊精一卟啉为主体分子构筑的超分子体系能更有效地模拟生物酶, 表现出优异的区域和立体选择性, 在仿生催化方面 将具有更广泛的应用前景.
\end{abstract}

关键词 环糊精; 卟啉; 超分子化合物; 构筑

\section{Advance in the Construction and Application of Cyclodextrin- Porphyrin Supramolecular System}

\author{
Chen, Shaoyun Zhou, Xiantai Ji, Hongbing* \\ (School of Chemistry and Chemical Engineering, Sun Yat-sen University, Guangzhou 510275)
}

\begin{abstract}
Molecular recognition and selective guest molecular inclusion are the unique performances of cyclodextrin, and porphyrin owns the behavior of biomimetic catalysis, electron transfer and light energy transfer. Based on the introduction of construction ways, the applications of cyclodextrin-porphyrins supramolecular system in biomimetic catalysis, life science, drug delivery and electron transfer were well reviewed. The cyclodextrin-porphyrins supramolecular system endowed with the advantages that concentrated the dual nature of porphyrins and cyclodextrin. The supramolecular system constructed by using the binding cyclodextrin-porphyrins as host molecular could more effectively mimic the behavior of enzymes, showing excellent regional and stereoselectivity. And it will be widely used in biomimetic catalysis.
\end{abstract}

Keywords cyclodextrin; porphyrin; supramolecular compound; construction

卟啉(Porphyrin)是一类由四个吡咯环通过次甲基相 连形成共轭骨架的大环化合物, 由于其独特的结构, 优 越的物理、化学及光学特征, 因此卟啉化合物在仿生催 化、光动力疗法、分子识别等领域都有广泛的应用 ${ }^{[1-3]}$. 环糊精 (Cyclodextrin, 简称 $\mathrm{CD}$ ), 是由环糊精葡萄糖转 移酶(CGT)作用于淀粉所产生的一组环状低聚糖, 常见 的环糊精有 $\alpha$-环糊精 $(\alpha-\mathrm{CD}), \beta$-环糊精 ( $\beta$-CD), $\gamma$-环糊精 $(\gamma$-CD). 环糊精具有 “内腔疏水, 外壁亲水”的特殊结构, 以及良好水溶性、优异的分子识别能力等性质, 目前环 糊精特别是 $\beta$ - $\mathrm{CD}$ 已被广泛应用于生物酶模拟、仿生催 化等领域 ${ }^{[4,5]}$. 最近刘海洋等 ${ }^{[6]}$ 根据不同结构卟啉砌块的 类型, 综述了二维与三维卟啉超分子的自构筑和应用方
面的进展．黄进等 ${ }^{[7]}$ 总结了环糊精包合作用诱导聚合物 自组装的研究进展. 从这些综述来看, 更多关注的是单 独以卟啉或环糊精通过自组装而成的超分子体系.

鉴于卟啉和环糊精各自独特的性质，1996 年 Breslow 课题组 ${ }^{[8]}$ 将环糊精与卟啉结合起来, 成功构筑 了以键联环糊精一卟啉为主体分子的超分子体系, 引起 了广大研究者的极大兴趣, 目前已有多个环糊精一卟啉 超分子体系见诸报道，并成功应用于催化、医药、生物 过程的模拟等领域 ${ }^{[9 \sim 11]}$. 根据环糊精一卟啉超分子体系 构筑方式的不同，本文详细综述了环糊精一卟啉超分子 体系在模拟酶催化、生命科学、药物控释、电子转移过 程等方面的应用进展.

\footnotetext{
*E-mail: jihb@mail.sysu.edu.cn; Tel.: 020-84113658, Fax: 020-84113654.

Received July 13, 2011; revised September 22, 2011; accepted November 15, 2011.

Project supported by the National Natural Science Foundation of China (Nos. 21036009, 20976203, 21176268), the Higher-Level Talent Project for Guangdong Provincial Universities (2010) and the Fundamental Research Funds for the Central Universities.

国家自然科学基金(Nos. 21036009, 20976203, 21176268)、2010 年广东省高等学校高层次人才项目、中央高校基本科研业务费专项资金资助项目.
} 


\section{1 通过包结作用构筑的环糊精一卟啉超分子体} 系

环糊精类似于蛋白质附属物, 借助非共价作用(疏 水作用、静电作用、氢键等)与卟啉包结后, 给卟啉提供 了一个疏水性环境, 可阻碍卟啉之间形成二聚体, 这种 包结作用可提高超分子体系的稳定性. 由此构筑的超分 子体系制备相对比较简单, 在生物医药、天然酶模拟等 方面具有良好的应用前景.

1990 年 Manka 等 ${ }^{[12]}$ 首次制备了四个苯基取代的卟 啉与环糊精的包结物, 为提高卟啉在水中的溶解性开辟 了全新的途径. 根据金属卟啉外环基团的水溶性差异, 通过分子间包结作用构筑的环糊精一卟啉超分子化合物 又可分为环糊精一水溶性卟啉的包结物和环糊精一脂溶 性卟啉的包结物两种类型.

\section{1 环糊精一水溶性卟啉的包结物}

EL-Hachemi 等 ${ }^{[13]}$ 合成了一系列磺酸基的水溶性卟 啉四-(4-磺酸基苯基)卟啉( $\mathrm{TPPS}_{4}, 1$ ), $\mathrm{TPPS}_{3}, 5,15$-二磺酸 基-10,20-二苯基卟啉( TPPS $_{20}$ ) 和 5,10-二磺酸基-15,20-二 苯基吓啉 $\left(\mathrm{TPPS}_{2 \mathrm{a}}\right)$ 与 $\beta-\mathrm{CD}, \gamma-\mathrm{CD}$ 形成的包结物, 除 $\mathrm{TPPS}_{2 \mathrm{a}}$ 没有形成包结物外, 其它三种卟啉与 $\beta-\mathrm{CD}, \gamma-\mathrm{CD}$ 都形成了包结物, 同时研究了这些包结物在水溶液中的 稳定性, 结果表明该包结物在水溶液中能稳定存在.

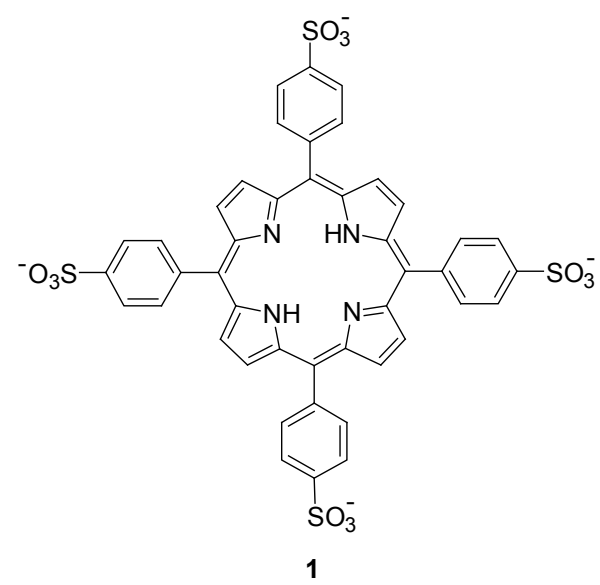

Mosinger 等 ${ }^{[14]}$ 研究发现双质子化的激发剂四-(4-磺 酸基苯基)卟啉 $\left(\mathrm{TPPSH}_{2}^{2+}, 2\right.$ ) 能与 $\beta$-CD 形成 $1: 1$ 的包 结物, 与未质子化的状态类似, 吡咯环上氮的质子化并 不影响 $\beta$ - CD 与吓啉之间的包结模式.

Hamai 等 ${ }^{[15]}$ 利用诱导圆二色光谱研究了四-(4-磺酸 基苯基)铁卟啉 $[\mathrm{Fe}(\mathrm{III}) \mathrm{TSPP}]$ 与环糊精及其衍生物形成 的包结物体系, 并对其结构和性能进行研究, 发现形成 的包结物具有良好的物理性能和化学性能. Kano 等 ${ }^{[16]}$ 制备了四-(4-磺酸基苯基)铁卟啉与环糊精衍生物形成 的包结物, 并将其用于模拟肌红蛋白的性质.

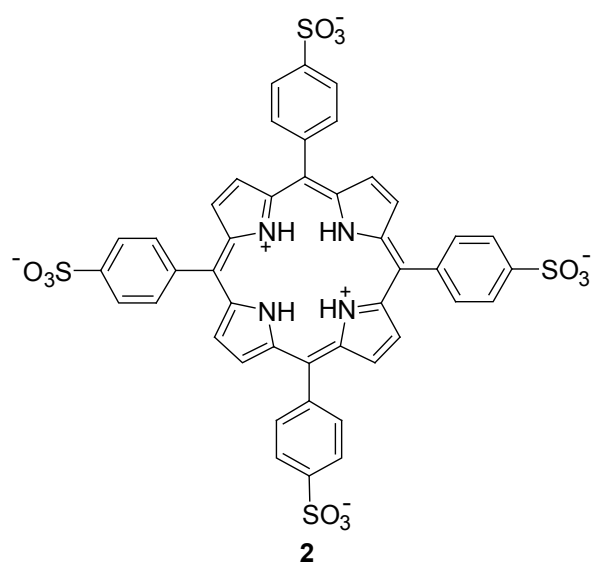

最近，国内郭玉晶等 ${ }^{[17,18]}$ 利用紫外可见光谱、荧光 光谱、电化学、极谱等表征手段研究了 meso-四-(2-差弪 基-5-磺酸基苯基)卟啉(THSPP), meso-四-(4-甲氧基-3-磺 酸基苯基)卟啉 $\left[\mathrm{T}(4-\mathrm{Mop}) \mathrm{PS}_{4}\right.$ 等多种水溶性卟啉与环糊 精及其衍生物的包结物超分子体系, 结果表明在 $\mathrm{pH}=$ 7.15 的磷酸盐缓冲溶液中, THSPP 与 6 种不同的环糊精 均形成了 $1: 1$ 的包结物. 阴离子型磺丁醚- $\beta$-环糊精 $(\mathrm{SBE}-\beta-\mathrm{CD})$ 与卟啉进行包结时, 表现出的包结能力相对 较弱，这说明除了疏水作用力、氢键以外，主客体之间 的电荷相互作用在包结过程中也起到了重要的作用, 相 对而言, 羟丙基- $\beta$-环糊精 (HP- $\beta$-CD) 的包结能力更强, 这一系列的研究为含卟啉类药物的控制释放提供了理 论基础.

Schneider ${ }^{[19]}$ 对卟啉和环糊精包结物的形成机理进 行了较为深入细致的研究, 这为卟啉和环糊精包结物超 分子体系的进一步应用提供了理论基础.

除了上述阴离子型的水溶性吓啉与环糊精及其衍 生物包结物超分子体系外, 国内外许多学者对于阳离子 型的水溶性吓啉与环糊精及其衍生物的包结物超分子 体系也进行了广泛的研究. 研究表明, 用环糊精包结后 的阳离子型卟啉及其金属络合物比阴离子型卟啉具有 更优异的生物活性 ${ }^{[20]}$.

Hamai 等 ${ }^{[21]}$ 利用紫外、荧光、圆二色谱等研究了在 $\mathrm{pH}=7.3$ 的缓冲溶液中, 阳离子型的水溶性卟啉四-(4甲基吡啶基)卟啉(TMPyP, 3)与环糊精及其衍生物形成 的包结物, 研究表明 TMPyP 与 $\alpha-\mathrm{CD}, \beta-\mathrm{CD}, \gamma-\mathrm{CD}$ 均形 成了 $1: 1$ 的包结物.

Qiu 等 ${ }^{[22]}$ 将水溶性的阳离子型卟啉 TPPOC3Py (4) 与 $\beta-\mathrm{CD}, \mathrm{HP}-\beta-\mathrm{CD}$ 在水溶液中制备了超分子包结物, 并 用紫外和核磁等对其进行了有效表征，结果表明 TPPOC3Py 与 $\beta$-CD 和 HP- $\beta$-CD 均形成了 $1: 1$ 的包结 物.

Mosinger 等 ${ }^{[14]}$ 也报道了 TMPyP 与四种环糊精形成 的包结物体系，利用紫外、核磁、苂光、毛细管区带电 


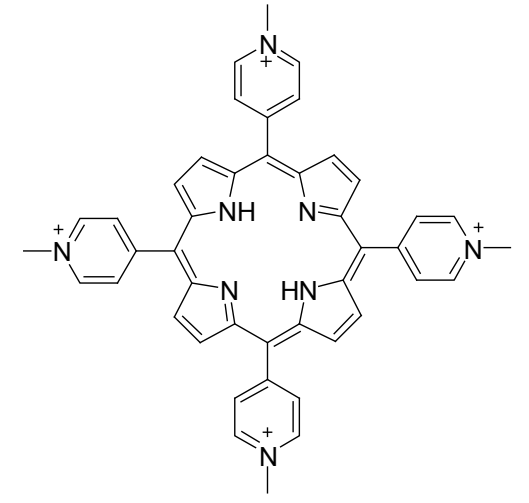

3

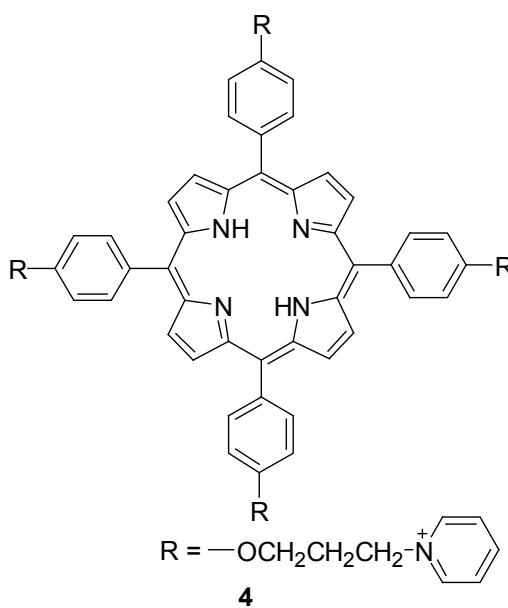

泳、质谱等表征方法进行了研究, 计算了包结比及包结 常数, 表明 TMPyP 与母体环糊精形成了 $1: 1,1: 2$ 两 种包结物, 包结模式是从环糊精的大口端进入.

\section{2 环糊精一脂溶性卟啉的包结物}

近几年来，脂溶性吓啉与环糊精的包结物体系也引

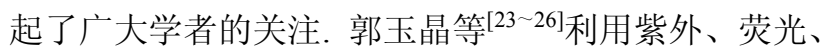
核磁等表征手段详细研究了 5-(4-硝基苯基)-10,15,20三-苯基卟啉 $(o$-NTPP, 5), 5-(对-羟苯基)-10,15,20-三-(4氯苯基)卟啉 $(p$-HTClPP), meso-四(2-噻吩基) $\mathrm{Mg}$ 卟啉等 几种脂溶性的卟啉与环糊精及其衍生物形成的包结物 体系, 研究表明不同的卟啉和不同的环糊精及其衍生物 形成不同的包结物，且包结方式、包结能力、相互作用 的方式也不同, 例如 5-吡啶基-10,15,20-三(对-氯苯基) 卟啉(PyTPP, 6)与 $\beta$-CD、七( $2,3,6$-三一氧-甲基)- $\beta$-环糊精 (TM- $\beta$-CD) 相互作用形成的包结物体系, 结果表明卟啉 与 TM- $\beta$-CD 形成了 $1: 1$ 的包结物, 而 PyTPP 与 $\beta$-环糊 精却未形成包结物, 证明了在包结过程中环糊精内腔的 性质起着重要作用.

此外, 作者还研究了 PyTPP 与 DNA 的相互作用, 结果表明, 卟啉环上很高的电荷密度, PyTPP 不是插入 DNA 的沟槽中, 而是沿着 DNA 的螺旋线在外侧发生包 结作用的. 而在 TM- $\beta$-CD 存在的条件下, PyTPP 进入了
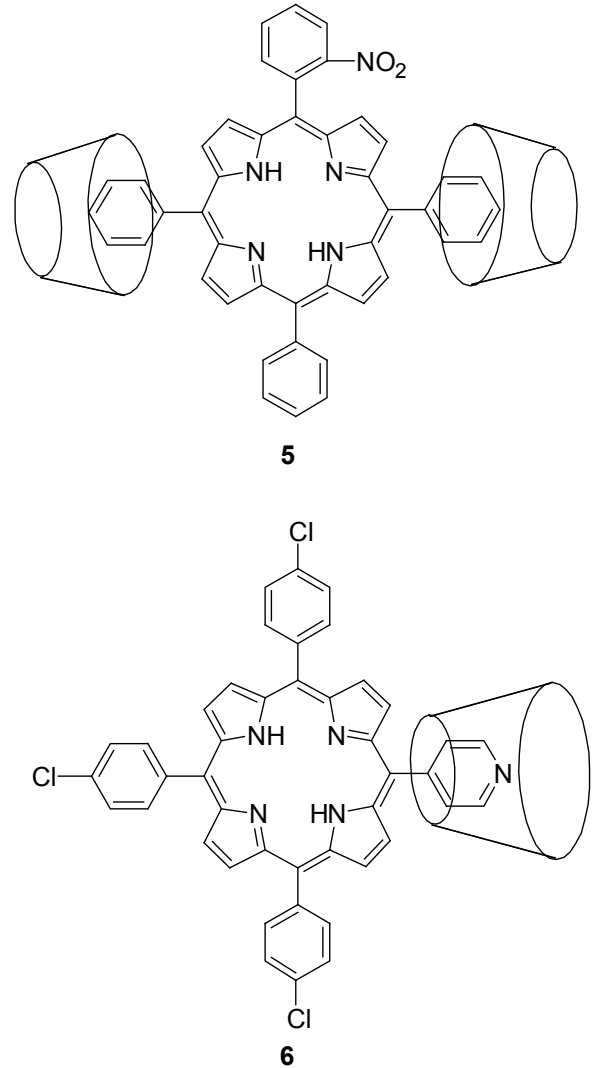

TM- $\beta$-CD 的空腔, 发生了包结作用, 而 PyTPP 与 DNA 的包结作用被抑制.

孔令宏等 ${ }^{[25,27]}$ 利用紫外-可见分光光度、苂光光谱 和 ${ }^{1} \mathrm{H}$ NMR 等表征方法详细研究了 $o$-NTPP 和 5-(2-羊茎苯 基)-10,15,20-三-(4-甲氧基苯基)卟啉 ( $o$-HTPP)两种脂溶 性卟啉与环糊精及其衍生物形成的包结物体系, 结果表 明 $o$-NTPP 与 TM- $\beta$-CD 形成了 $1: 2$ 的包结物, 而与 $\alpha-\mathrm{CD}, \beta-\mathrm{CD}, \gamma-\mathrm{CD}$ 和羧甲基- $\beta$-环糊精 (CM- $\beta$-CD) 4 种环 糊精均形成 $1: 1$ 的包结物, 从而判断出 5 种环糊精对 $o$-NTPP 包结能力的大小, 其中 TM- $\beta$-CD 表现出的包结 能力最佳. 而另一种卟啉 $o$-HTPP 在与 $\alpha-\mathrm{CD}, \beta-\mathrm{CD}$, TM- $\beta$-CD, SBE- $\beta$-CD, HP- $\beta-\mathrm{CD}, \gamma-\mathrm{CD}$ 的包结过程中, 结 果表明 $o$-HTPP 与 TM- $\beta$-CD 形成了 $1: 2$ 的包结物, 与 其余 5 种卟啉却均形成了 $1: 1$ 的包结物, 这是因为与 TM- $\beta$-CD 包结时氢键起了重要的作用.

通过包结作用构筑环糊精一卟啉超分子体系研究一 般集中于主体分子即环糊精的结构修饰，而对于包结物 体系中客体分子(卟啉分子)结构对包结性能影响的研究 却相对甚少. 胡羽等 ${ }^{[28]}$ 合成了 5 种脂溶性烷氧基苯基卟 啉，探讨了不同取代位置、不同链长的烷氧基对脂溶性 烷氧基苯基卟啉与不同空腔直径的环糊精的包结物体 系的影响, 结果表明在三种取代基相同或相近但取代位 置不同的烷氧基苯基卟啉中, 其与 $\alpha-\mathrm{CD}$ 包结常数大小 顺序为: 邻位 $>$ 对位 $>$ 间位. 三种取代位置相同但取代 
基链长不同的烷氧基苯基卟啉与羟基吓啉中, 链长越长 其包结常数越小. 在 meso-四(对正丁烷氧基苯基)卟啉 [T(4-BOP) $\left.\mathrm{PH}_{2}\right]$ 与三种环糊精的包结反应中, 相对于 $\beta$ - $\mathrm{CD}, \gamma-\mathrm{CD}$ 两种环糊精, $\alpha-\mathrm{CD}$ 具有更强的包结能力, 与 $\mathrm{T}(4-\mathrm{BOP}) \mathrm{PH}_{2}$ 具有最佳的空腔匹配尺寸.

2010 年该课题组 ${ }^{[29]}$ 首次合成了一种含有肽键的四 苯基卟啉衍生物 5-(4-苯甲酰亚胺基苯基)-10,15,20-三苯 基卟啉 $\left(\mathrm{BATPPH}_{2}\right.$ )及其锌配合物(BATPPZn), 并研究了 它们在中性磷酸盐缓冲溶液中与 $\alpha, \beta, \gamma-\mathrm{CD}$ 相互作用形 成的包结物体系, 结果表明 $\mathrm{BATPPH}_{2}$ 和 BATPPZn 与 $\alpha$, $\beta, \gamma-\mathrm{CD}$ 均形成了 $1: 1$ 的包结物, 由于这两种卟啉衍生 物的尺寸、几何形状与 $\gamma-\mathrm{CD}$ 的空腔尺寸和性质最为匹 配, 与 $\gamma-\mathrm{CD}$ 的包结常数最大, 因此 $\gamma-\mathrm{CD}$ 表现出最强的 包结能力. $\mathrm{Zn}^{2+}$ 的配位作用使包结物的稳定性降低, 但 对包结物的包结比并没有产生很大影响. 通过核磁共振 表征可知 BATPPH ${ }_{2}-\gamma-\mathrm{CD}$ 和 BATPPZn- $\gamma-\mathrm{CD}$ 超分子体系

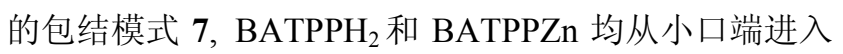
$\gamma$-CD 的空腔.

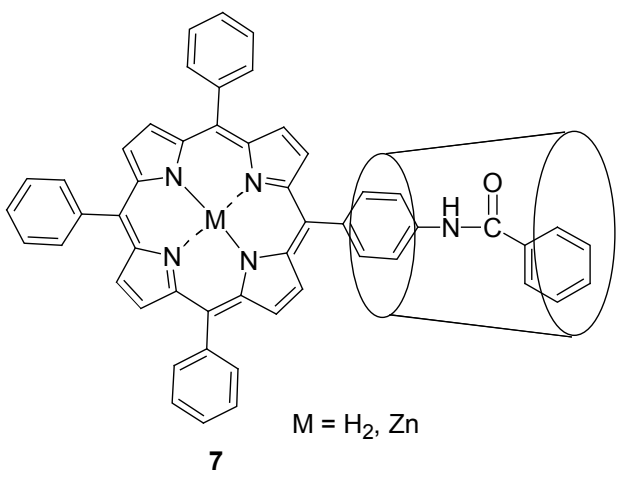

\section{2 通过自组装构筑的环糊精一卟啉超分子体系}

为了构筑高度有序、形貌可控、稳定的卟啉纳米结 构, 研究者通过非共价作用(如氢键等)在水溶液中成功 构筑了多种环糊精与卟啉的自组装体系, 并通过紫外可 见吸收光谱、 $X$ 射线光电能谱(XPS)、原子力显微镜 (AFM)、核磁共振(NMR)、透射电子显微镜(TEM)、X 射线衍射(XRD)等手段进行了表征, 由此构筑的环糊 精一卟啉超分子体系对于研究酶催化等生物过程的模 拟、生命科学等具有重要意义.

Carofiglio 等 ${ }^{[30]}$ 通过氨基将卟啉和环糊精相键联建 立了一种新的水溶性的模拟酶模型 8 (Scheme 1), 用于 研究主体和疏水性底物之间的作用. 研究发现, 它在水 溶液中可以形成 $1: 1$ 的自组装体系. 在酸性条件下, 由 于卟啉环中 $\mathrm{N}$ 原子的质子化使其带有两个正电荷, 使得 产物具有两性离子的性质, 得到了因静电作用形成的二 聚体 9c, 而在碱性条件下, 因疏水作用易形成顺式 9a 和反式 9b 两种结合模式的二聚体.
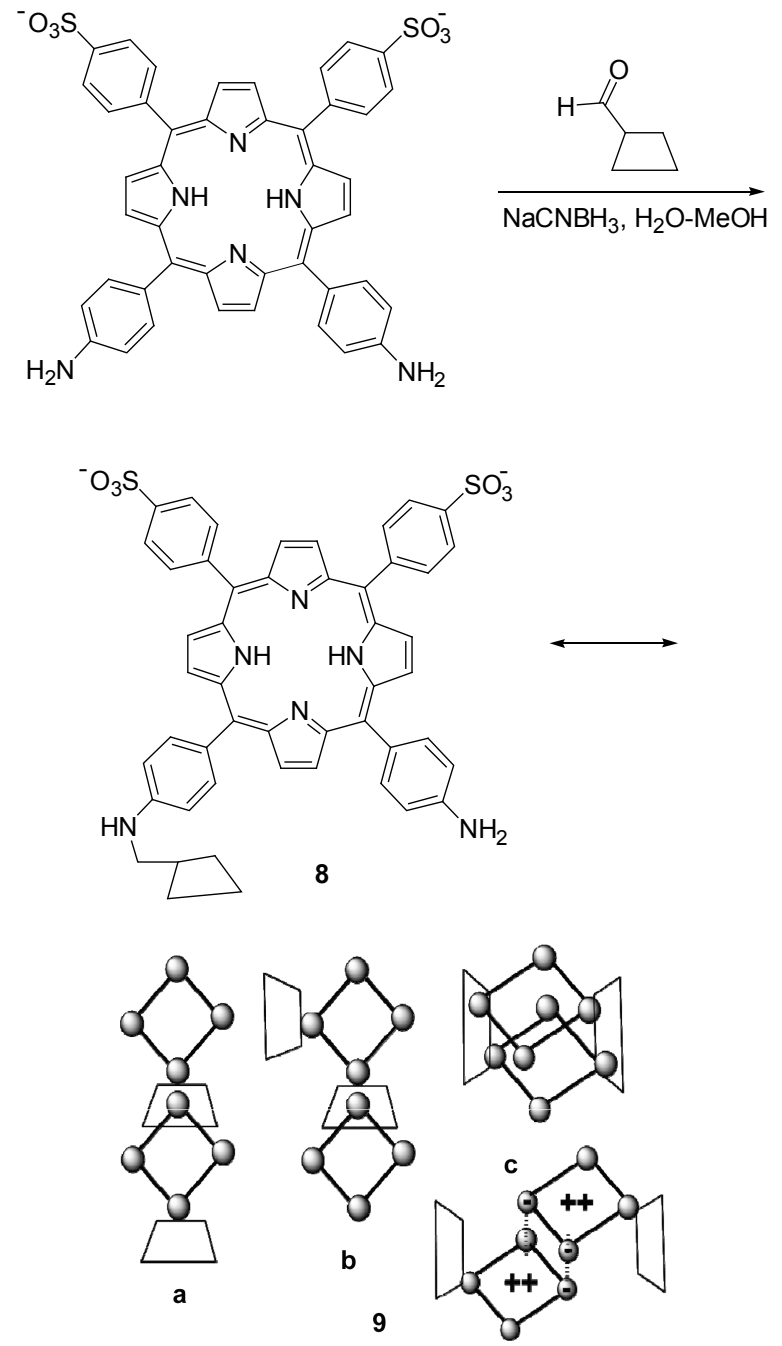

Scheme 1

Kano 等 ${ }^{[31]}$ 报道了两种 $\beta$ - $\mathrm{CD}$ 与卟啉键联的超分子 化合物, 它们作为主客体单元, 在水溶液中与 5-苯 基-10,15,20-三(3,5-二羒基苯基)锌卟啉自发构筑了 $1: 4$, $1: 1$ 的多卟啉自组装阵列. 在 $1: 4$ 的配合物中有 4 个 环糊精，电子转移效率达到 $85 \%$, 在 $1: 1$ 的配合物中只 有一个环糊精，电子转移效率达到 $93 \%$, 表明 $\beta$-CD 在 卟啉环周围的空间取向影响其电子转移效率.

Sasaki 等 ${ }^{[32]}$ 通过合成的带有四个全甲基化 $\beta$ - $\mathrm{CD}$ 的 环糊精一卟啉 (4CD-TPP) 的化合物, 实现了在水溶液中 与四-(4-磺基苯)卟啉( $\mathrm{TPPS}_{4}$ )形成 $2: 2$ 的自组装体系. 由于静电力作用(如 $\pi-\pi$ 键的作用)会导致卟啉在水相中 聚合，使得卟啉纳米结构不规则.

Fathalla 等 ${ }^{[33]}$ 通过弱化 $\pi-\pi$ 键的作用, 选用键联的环 糊精与卟啉的超分子与修饰过的金刚烷 $\mathbf{1 0}$ 通过自组装, 在水溶液中构筑了一种稳定的、高度有序的卟啉纳米线. 通过表面显微技术和苂光能量转移实验, 证明了其稳定 性. 


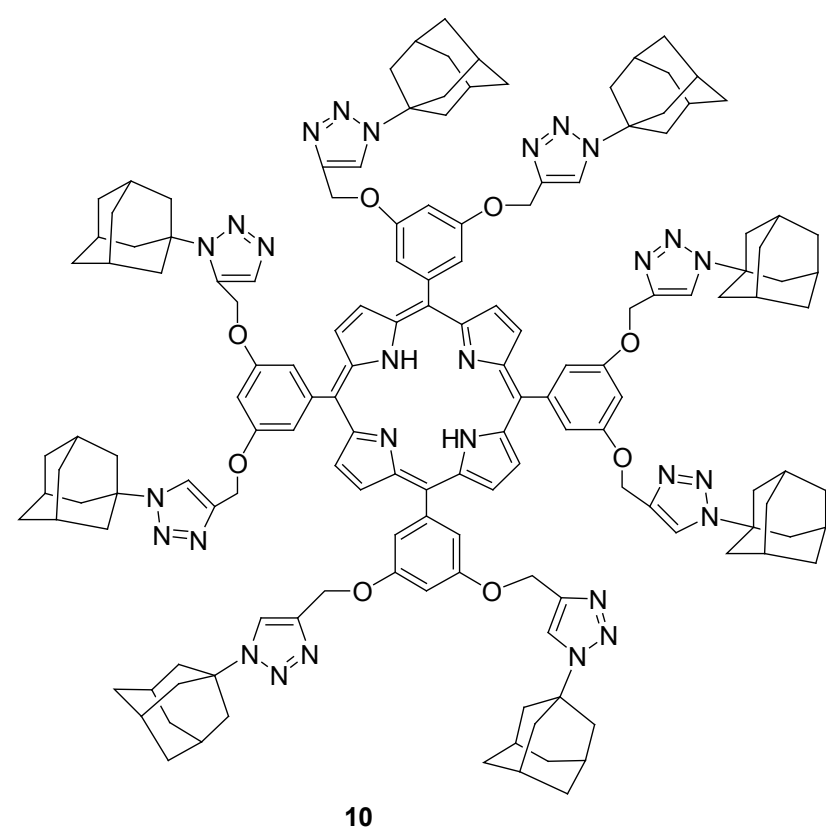

Liu 等 ${ }^{[34]}$ 报道了经着基喹啉修饰过的全甲基化的 $\beta$-CD 11 与 $\mathrm{Zn}^{2+}$ 形成了化学计量比是 $2: 1$ 的配合物, 该 配合物与四-(4-磺基苯)锌卟啉形成了三组分的超分子 自组装体系, 并通过 UV, XRD, STM, TEM 和荧光等进 行了结构表征, 由荧光光谱结果可知该自组装体系在水 中几乎不发射绿色荧光, 原因在于能量转移过程, 如果 在疏水环境中, 由于该自组装体系被破坏, 会发射出很 强的绿色荧光. 通过苂光来实现的细胞着色实验进一步 指出了与细胞膜作用时, 该自组装体系被破坏会释放出 $2: 1$ 的锌配合物和四-(4-磺基苯)锌卟啉, 且发现 $2: 1$ 的锌配合物仍然留在细胞膜内, 而四-(4-磺基苯)锌卟啉 则进入了细胞. 这种超分子自组装体系跨膜的分解行 为, 在含有阴离子型卟啉骨架的药物运输方面具有潜在 的应用价值.

$\mathrm{Gu}$ 等 ${ }^{[35}$ 报道了一种修饰过的 $\beta$ - $\mathrm{CD}$ 和四-(4-磺酸基 苯基)吓啉通过主客体之间的相互作用在水溶液中形成 了高度有序的线性自组装体系(Scheme 2), 并通过紫 外、核磁、原子力显微镜、透射电子显微镜等多种手段 进行了表征, 研究发现该自组装体系具有良好的稳定性 和水溶性, 主客体之间的苂光共振能量转移量子产率可 达 $94 \%$, 这方面的研究在生命科学领域具有广阔的应用 前景.

$\mathrm{Yu}$ 等 ${ }^{[36]}$ 建立了一种新的双功能酶模型, 融合了谷 胱甘肽过氧化物酶(GPx)和超氧化物歧化酶(SOD)的功 能, 该模型是由金属锰叶啉和修饰过的环糊精通过自组 装构筑的超分子体系, 该双功能酶模型中, 其中的金属 锰卟啉是超氧化物歧化酶(SOD)的有效活性位, 而修饰 过的环糊精的碲酸空腔具有谷胱甘肽过氧化物酶(GPx)

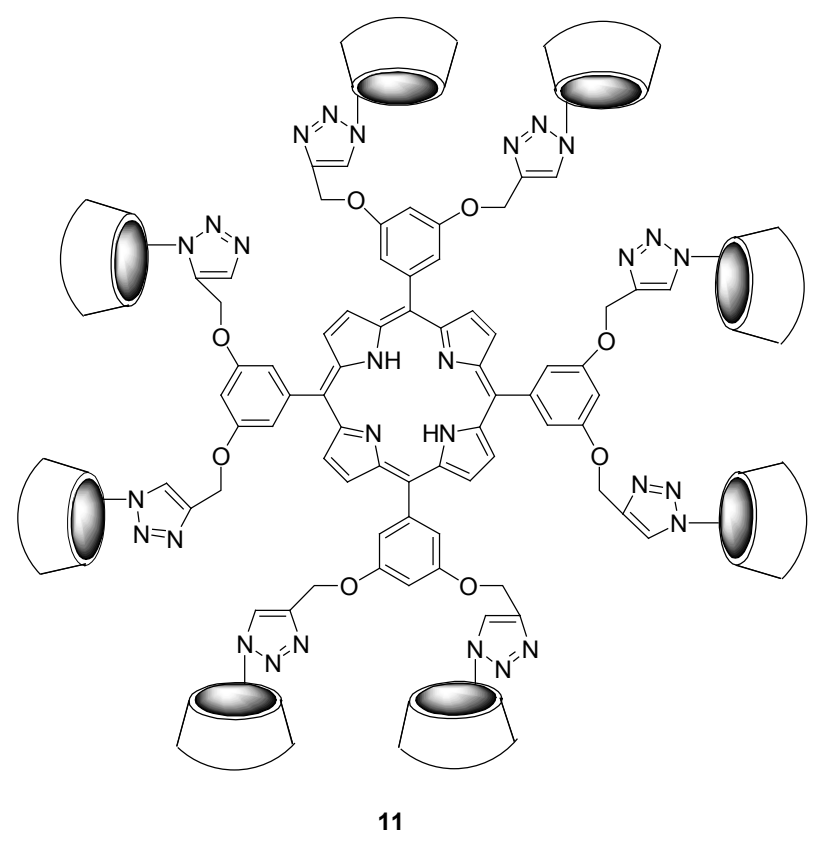

的活性, 因此体现出良好的双功能效果, 与依布硒啉相 比，疗效显著得到提高. 更值得一提的是，这种超分子 人工模拟双功能酶模型具有良好的热稳定性.

Kiba 等 ${ }^{\left[{ }^{[7]}\right.}$ 报道了一种 $\beta$ - $\mathrm{CD}$ 与锌卟啉键联的超分子 $(\mathrm{ZnP}-\beta-\mathrm{CD})$ 在水/乙醇混合溶剂中的自组装体系，由光 谱数据以及原子力显微镜图像可知在一定浓度条件下, 锌卟啉被包结到 $\mathrm{ZnP}-\beta-\mathrm{CD}$ 的 $\beta-\mathrm{CD}$ 的空腔, 在自组装过 程中形成了锌卟啉的 $\mathrm{J}$ 型聚集体.

Mazzaglia 等 ${ }^{[38]}$ 报道了一种新型的两性环糊精与阴 离子型卟啉构筑而成的自组装体系，该自组装体系可以 顺利地进入到肿瘤细胞中，由于环糊精包含有荧光发色 团，因此体现出它的多功能性，实现了在肿瘤细胞内同 时运输和检测载体和药物. 通过各种光谱技术分析，可 知该自组装体系在生理条件下是稳定的, 可以在检测癌 细胞方面起到有效的作用.

\section{3 以键联环糊精一卟啉主体分子构筑的超分子 体系}

在环糊精一卟啉超分子体系的构筑中，除了采用包 结作用、自组装等构筑方式外, 也有文献报道以键联环 糊精一卟啉主体分子构筑的超分子体系，但报道相对较 少. 以键联环糊精一卟啉主体分子构筑的超分子体系稳 定性好，不仅改善了卟啉分子在水中的溶解性能，同时 还避免了卟啉分子因自聚而造成的催化剂失活, 实现了 在催化氧化过程中保护卟吩环与它的芳香取代基不受 其它活性基团的侵扰，提高了稳定性 ${ }^{[39]}$. 这类超分子化 合物可以作为单加氧酶、超氧歧化酶等模型，通过模拟 酶的性质、微环境等实现了在温和条件下对分子氧的活 


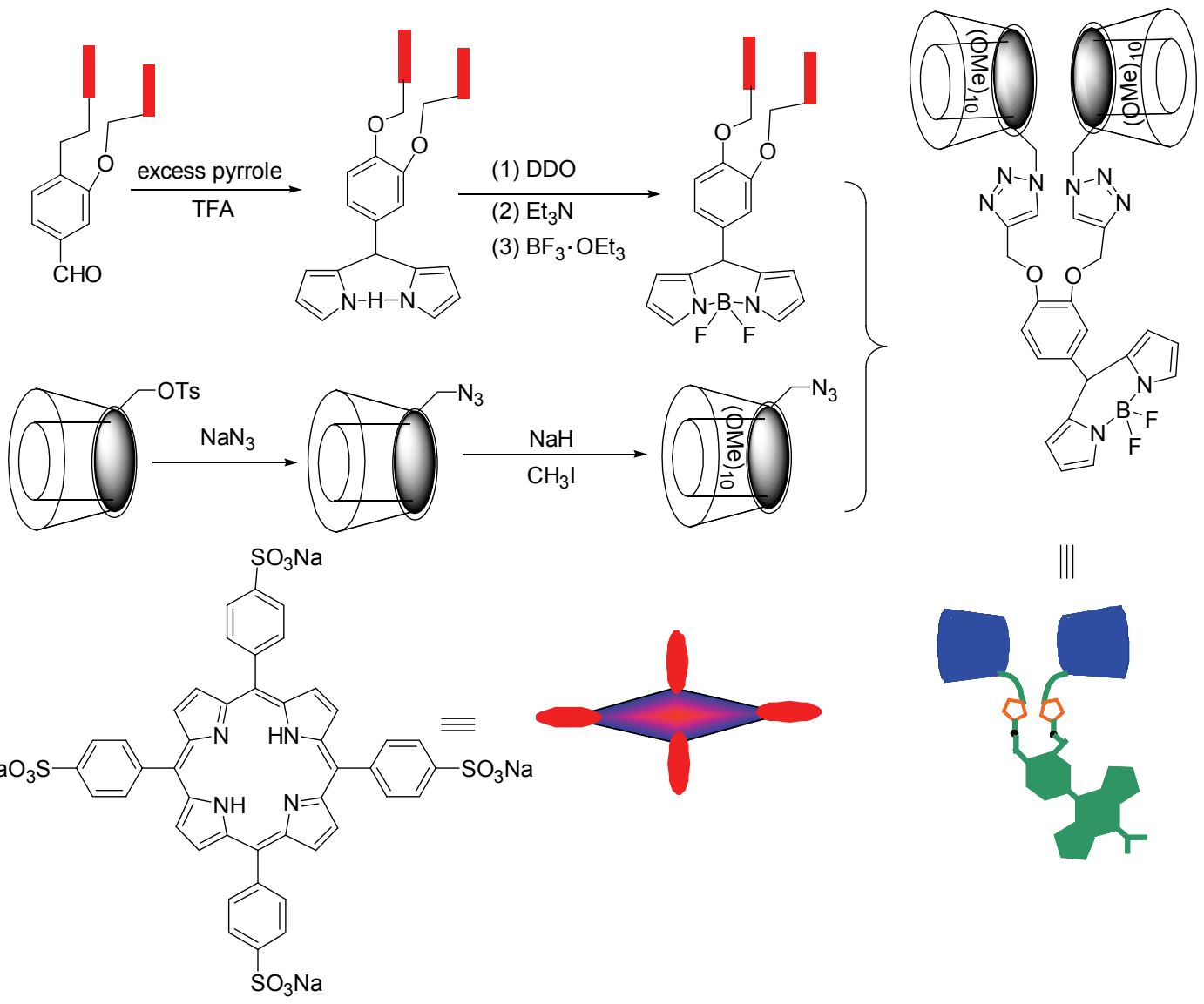

Scheme 2

化, 表现出高的催化活性和选择性, 在光合作用等生物 过程的模拟、生命科学领域有广阔的应用前景.

Breslow 建立了多个环糊精一卟啉超分子模拟酶模 型, 并在模拟细胞色素 P-450 的催化氧化方面做了很多 工作. 1996 年该研究小组 ${ }^{[8]}$ 利用金属卟啉的催化性能和 环糊精对反应底物的选择性，通过颈基键合得到了 12 15. 其中在模拟细胞色素 P- 450 酶时, 卟啉 $-4 C D$ 12、卟啉-2CD 13 作为主体分子利用环糊精的疏水空腔 有效识别了甾体物质, 表现出优异的选择性, 实现了在 含有羟基和 $\mathrm{C}=\mathrm{C}$ 条件下, 选择性催化氧化活性较低的 饱和碳.

该研究组随后将 P-450 酶活性中心的金属卟啉分子 与四个环糊精分子相键联构成了一种新的小分子 P-450 模拟酶模型 4CD-4F 苯卟啉 16, 以该酶模型为主体分子, 依靠几何识别可选择性氧化位于中心金属附近的不活 泼碳原子, 实现了催化甾体的特异性羟基化反应 ${ }^{[40]}$, 产 率可达到 $95 \%$, 表现出很高的稳定性和优异的选择性. 对含有仲羟基和碳碳双键官能团的甾体仍可识别, 表现 出优异的区域和立体选择性, 实现了特异性羟基化反 应. 如对雄(甾)衍生物 179 号碳位置的选择性羟基化反 应具有良好的效果，同时提供了潜在的皮质甾类前

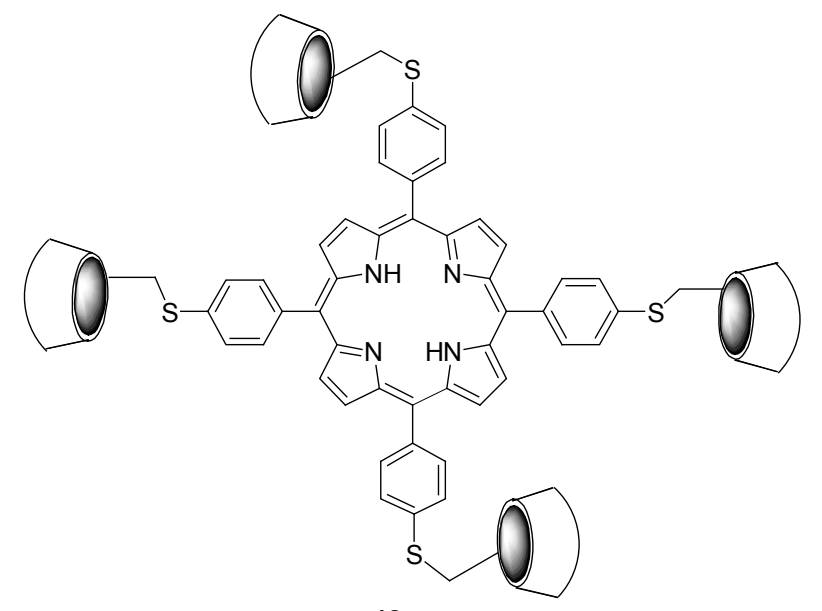

12

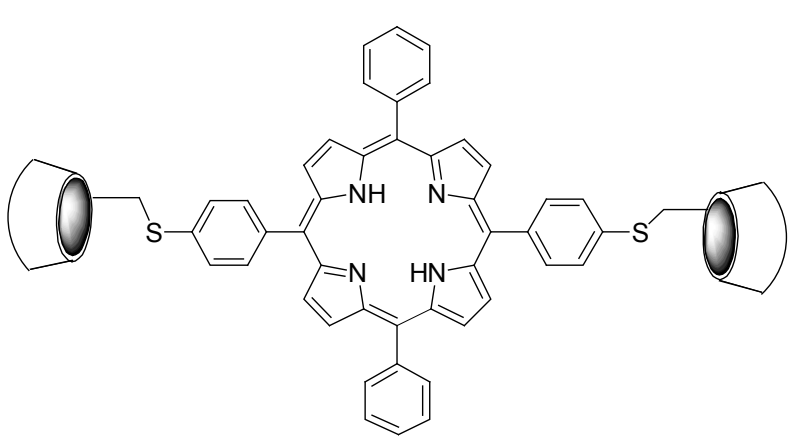

13 

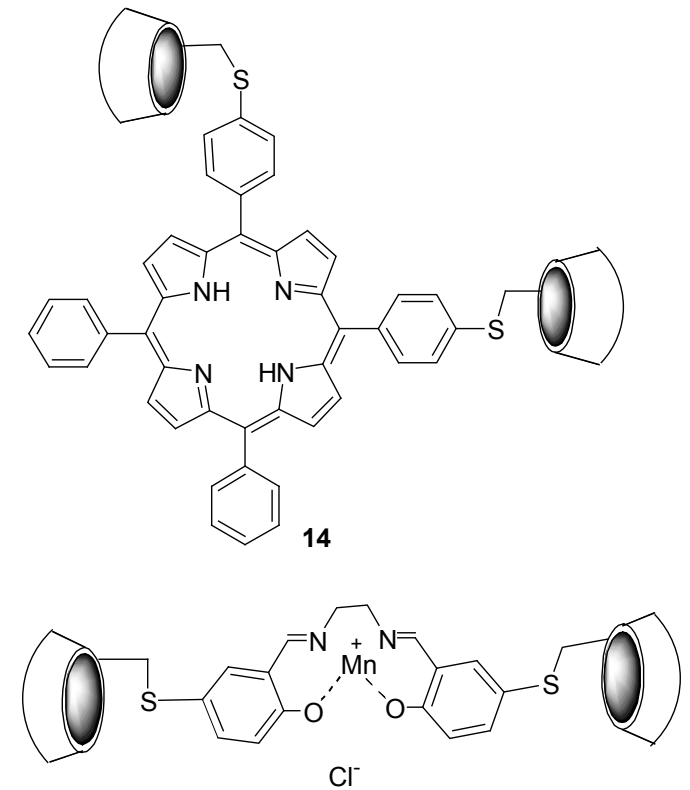

15

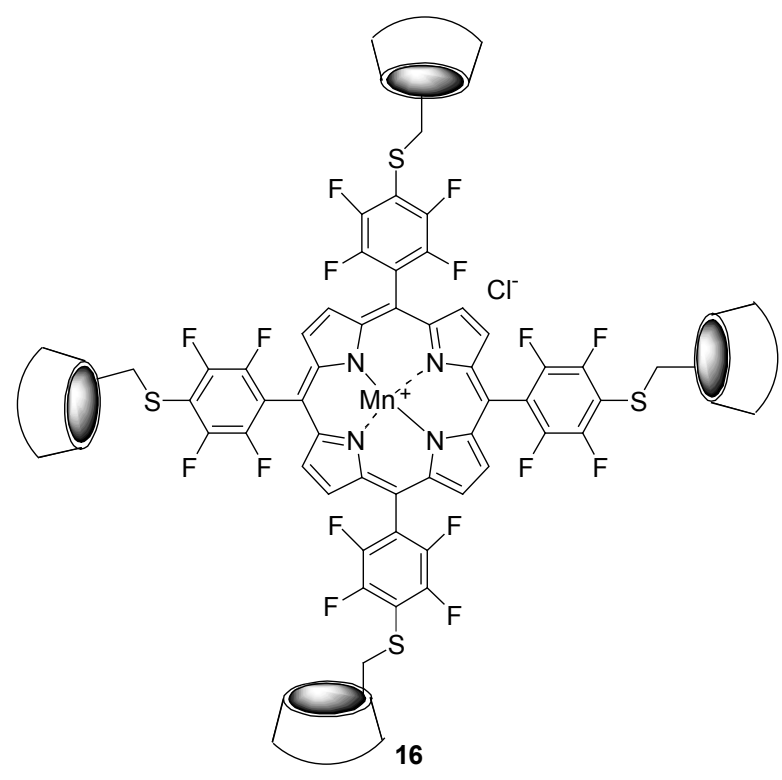

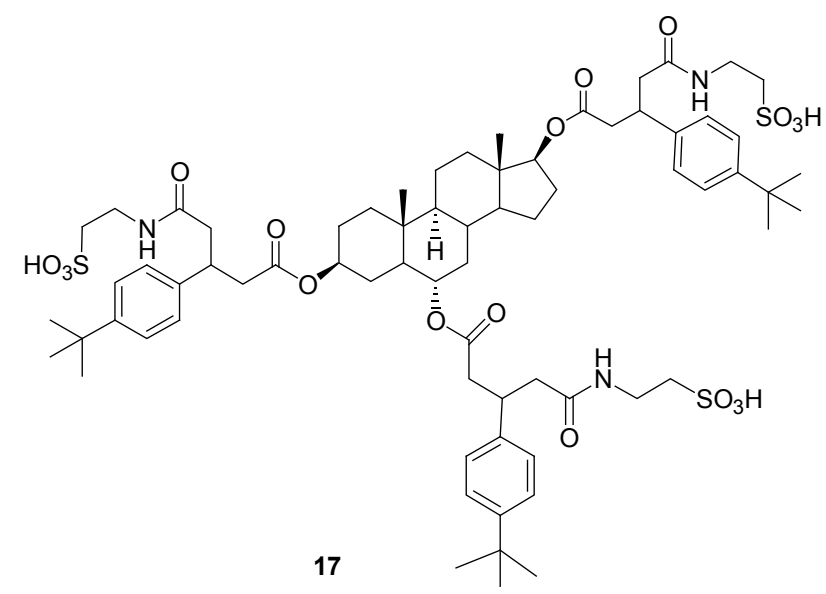

体，具有重要实在意义.

通过在催化剂体系中引入轴向配体，屏蔽金属卟啉 的一面，使得氧原子和反应底物位于卟啉环的同一面， 合成了化合物 18, 发现在催化羟基化反应中，高价金属 活性物上的氧原子更易转移给反应底物，催化剂的活性 转化数可达到 $2000^{[41]}$.

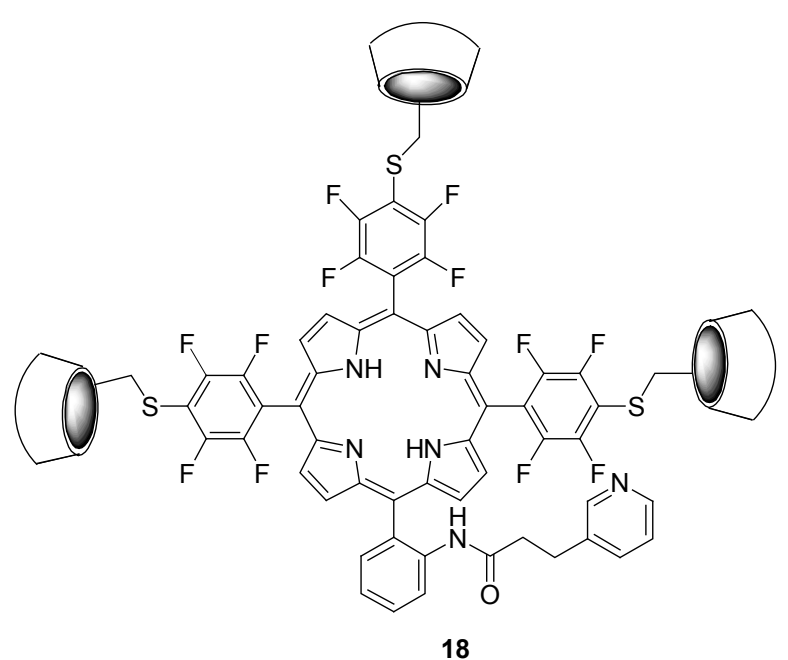

日本学者 Kuroda 等 ${ }^{[42,43]}$ 通过环糊精的衍生物与吡 咯的缩合反应合成了具有夹心结构的水溶性卟啉桥连 环糊精卟啉-2CD 及其亚铁配合物 19, 报道了在磷酸盐 的缓冲溶液中, 以亚碘酰苯 $(\mathrm{PhIO})$ 为氧化剂，用带有疏 水空腔的卟啉-2CD 亚铁配合物催化剂催化疏水烯烃(环 己烯)的环氧化反应，环氧化物的收率可达 $55 \%$, 而在相 同条件下，改用化合物 $\mathbf{2 0}$ 作催化剂，仅有微量的环己烯 被氧化(收率 $<2 \%=$. 由于烯烃和亚碘酰苯在缓冲溶液 中的溶解度很小, 但是环糊精的疏水空腔对底物环己烯 和氧化剂 PhIO 能有效识别, 进而促进了对底物的催化 环氧化反应. 该催化剂良好的水溶性及其卟啉轴向的环 糊精疏水空腔结构, 引起了很多学者在模拟血红蛋白酶

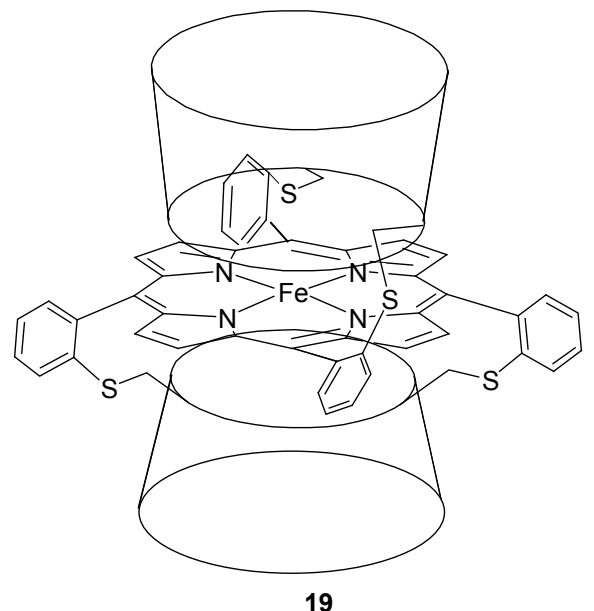




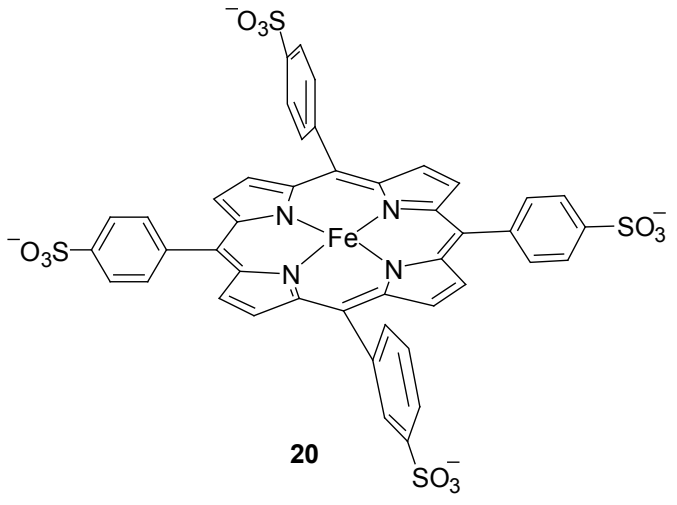

的仿生催化方面进行进一步的研究. Kuroda 等 ${ }^{[44]}$ 还利用 夹心结构的卟啉-2CD 催化剂活化分子氧而产生单线态 氧, 进而通过单线态氧氧化亚油酸, 该反应表现出一定 的区域选择性和立体选择性.

Weber 等 ${ }^{[45]}$ 在模拟细胞色素 P-450 的对映选择性氧 化反应中, 利用七-(2,6-全甲基化)- $\beta$-环糊精与四苯基 $\mathrm{Fe}(\mathrm{III})$ 卟啉和四苯基 $\mathrm{Mn}(\mathrm{III})$ 卟啉合成了一种以 $-\mathrm{OCH}_{2} \mathrm{CH}_{2} \mathrm{CH}_{2}$ 一键联的环糊精一卟啉超分子 21 , 首次 实现了 $\mathrm{O}_{2}$ 为氧源, 在可见光照射下, 利用环糊精一卟啉 超分子的手性空腔实现了有效识别 $(S)-(-)-\alpha$-蒎烯和 $(R)-(+)-\alpha$-蒎烯组成的外消旋体, 进行催化反应, 最高 $e e$ 值可达到 $67 \%$.

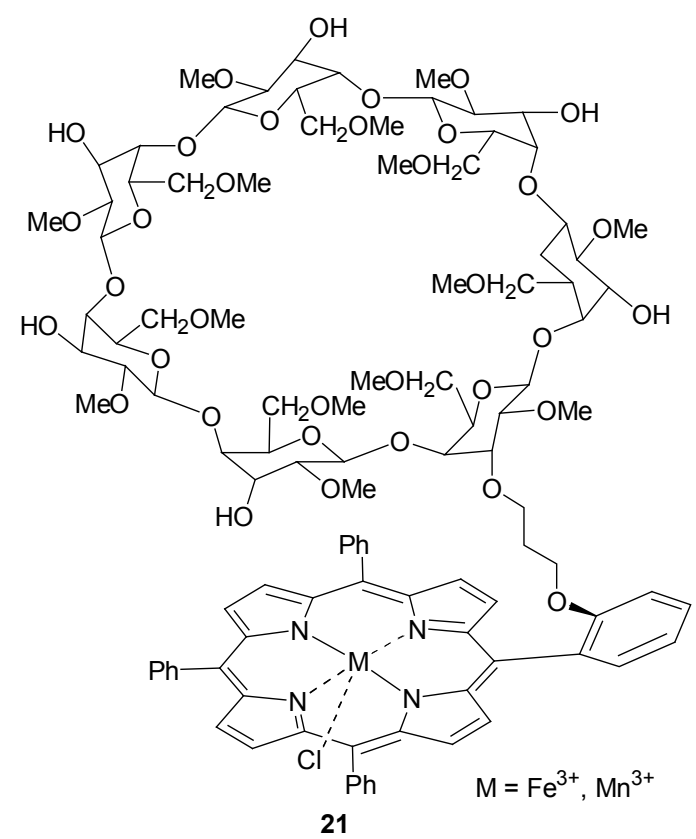

French 等 ${ }^{[46-48]}$ 构筑了以 $\beta$-环糊精与卟啉键联为主 体的超分子化合物来模拟 $\beta, \beta^{\prime}$-胡萝卜素 $15,15^{\prime}$-单充氧酶 的性质. 以该超分子化合物为催化剂, 叔丁基过氧化氢 为氧化剂, 通过环糊精的疏水空腔对 $\beta, \beta^{\prime}$-胡萝卜素端基 的有效识别, 实现了选择性地控制断裂反应底物的双
键，表现出优异的区域选择性，所得反应产物与 $\beta, \beta^{\prime}$-胡 萝卜素 15,15'-单充氧酶催化氧化得到的反应产物相似.

由于超氧化物歧化酶(SOD)能有效地抑制癌细胞的 增长，但由于成本高，提取困难，易失活等原因，在生 物医学应用上很受限制, 因此制备能消除各种活性氧的 模拟酶成为研究的热点.

Grove 等 ${ }^{[49]}$ 提出了酶模型 Mn(III)TMPyP 和 Fe(III)TMPyP, 对消除 $\mathrm{O}_{2}^{--}$和降低 $\mathrm{ONOO}^{-}$活性进行了研究, 并对 $\mathrm{Fe}(\mathrm{III}) \mathrm{TMPyP}$ 分解 $\mathrm{ONOO}^{-}$的机理进行了讨论, 提 出了两种反应路径, 认为在 $\mathrm{ONOO}^{-}$过量的情况下, 生 成氧合 $\mathrm{Fe}(\mathrm{IV})-\mathrm{ONOO}^{-}$中间体的反应路径为主.

李早英等 ${ }^{[00,51]}$ 证实了钉、镇等金属卟啉具有消除 $\mathrm{O}_{2}^{--}$和抗脂质过氧化作用, 但金属卟啉的溶解度很低, 因此提高金属卟啉作为消除氧自由基酶模型物的亲水 性是主要问题, 结合环糊精良好的水溶性、分子识别能 力和立体选择性等特点, 成功合成了两种以 $-\mathrm{CH}_{2} \mathrm{HNPh}$ 一键联的环糊精一卟啉超分子作为消除氧自 由基酶模型物(Schemes 3 和 4), 并利用核磁、质谱、红 外和紫外等分析手段进行了表征，由于环糊精的空腔外 壁亲水, 对微环境的有效识别, 提高了金属卟啉的水溶 性, 有利于体内有害物的清除.

2010 年 Kralova 等 ${ }^{[52]}$ 报道了一系列新的含氟卟啉和 环糊精通过醚键相键联的超分子化合物 22, 并有效识 别各种药物分子, 成功构筑了多个超分子体系, 并应用 于多功能药物传递和各种癌症治疗, 研究表明由于环糊 精的疏水空腔对于非水溶性药物的有效识别, 使得药物 可以高效运输, 通过一定波长的光照射, 改变卟啉的光 化学性质, 实现了在肿瘤细胞中的选择性分布, 达到了 双重治疗的效果.

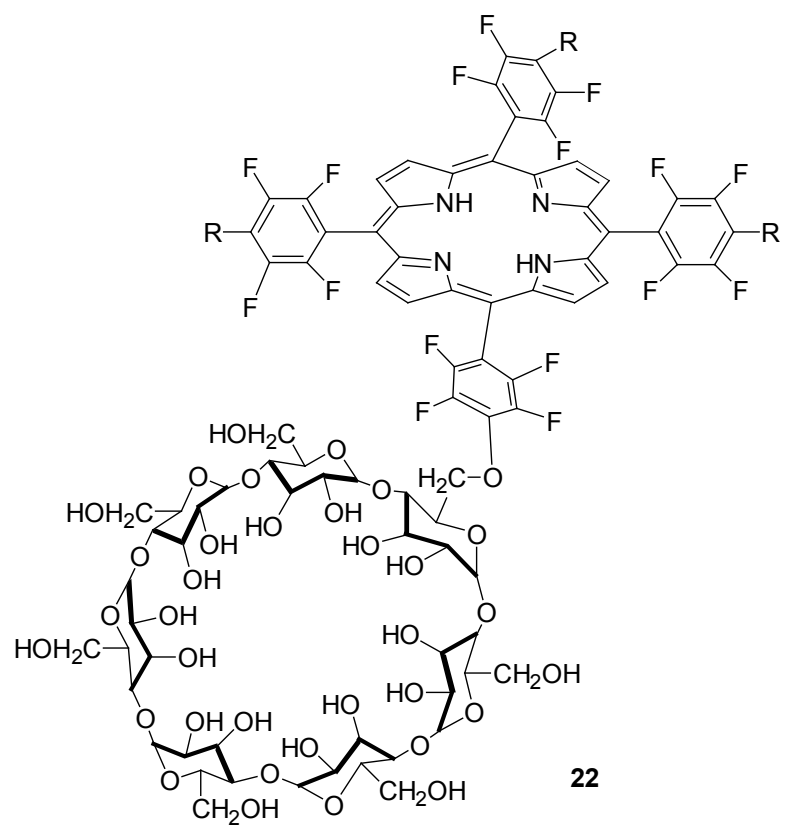




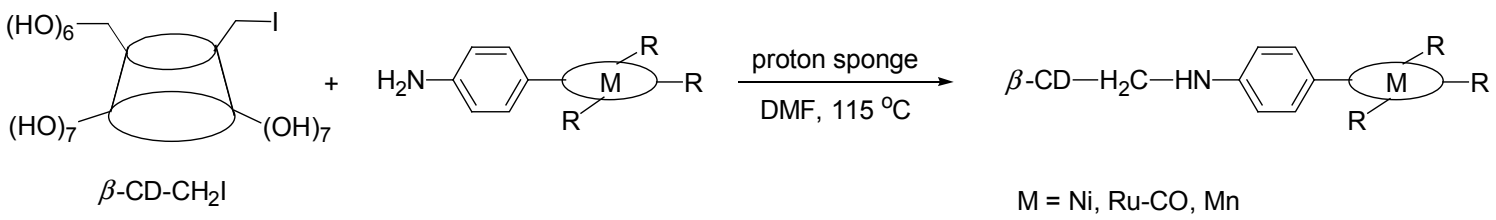

Scheme 3
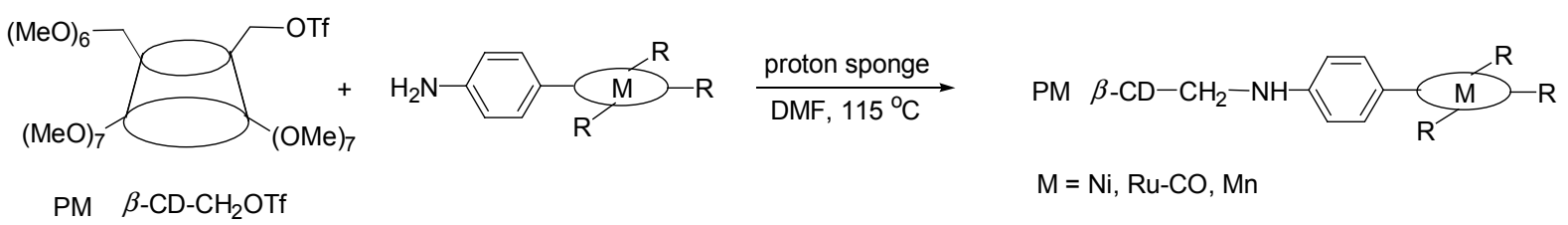

Scheme 4

为了实现在水溶液中模拟人工酶的性质, Chen 等 ${ }^{[53]}$ 通过含有环糊精的苯甲醛与吡咯直接缩合得到连 有四个 $\gamma-\mathrm{CD}$ 和两个卟啉的化合物, 通过系列的光谱研 究表明, 该环糊精一卟啉超分子化合物结构特殊, 含有 多个环糊精空腔, 其中的吓啉环部分还可以通过 $\pi-\pi$ 作 用或者疏水作用与客体分子发生作用形成超分子体系, 因此作者推测其具有多重识别能力和催化作用, 目前还 在研究中.

\section{4 结论与展望}

通过总结归纳了近年来国内外对环糊精与卟啉超 分子体系的研究, 可知环糊精一卟啉超分子体系可以通 过包结作用、自组装以及以键联环糊精一卟啉主体分子 进行构筑. 通过包结作用而构筑成的超分子体系主要对 于研究包结方式、包结机理以及卟啉类药物的应用及控 制释放具有研究意义, 而通过自组装而成的环糊精与卟 啉超分子体系在模拟酶催化、生命医药等方面有广泛的 应用, 以键联环糊精一卟啉主体分子构筑而成的超分子 体系能够有效地模拟各种生物酶, 实现各种催化反应, 例如在有羟基和 $\mathrm{C}=\mathrm{C}$ 存在的条件下, 实现了选择性催 化氧化活性较低的饱和碳, 并且表现出很高的立体选择 性、区域选择性.

环糊精及衍生物与卟啉构筑的超分子体系最大的 特点就是具有卟啉和环糊精及衍生物的双重性质, 更能 接近模拟生物酶的催化行为, 但目前的研究主要还是局 限在环糊精一卟啉单一的包结物的制备、结构表征方面, 而对于以键联环糊精一卟啉主体分子构筑的超分子体系 研究相对较少, 特别是这种超分子体系在仿生催化氧化 中的应用例子十分有限.

综上所述，环糊精一卟啉超分子体系在模拟酶催化、 生命科学、药物控释、电子转移等过程都具有广阔的应 用前景. 除了包结作用和自组装外, 如何有效地构筑出 不同类型的以键联环糊精一卟啉主体分子的超分子体系
以及在仿生催化中应用将是今后发展的一个重要方向. 随着新的环糊精一卟啉超分子体系的不断构筑，其在水 相中仿生催化氧化、微量有机物降解等方面的应用将会 得到更深入的拓展.

\section{References}

[1] Meunier, B. Biomimetic Oxidations Mediated by Metal Complexes, Imperial College Press, London, 2000.

[2] Lovell, J. F.; Liu, T. W. B.; Chen, J.; Zheng, G. Chem. Rev. 2010, $110,2839$.

[3] Haas, K. L.; Franz, K. J. Chem. Rev. 2009, 109, 4921.

[4] Villalonga, R.; Cao, R.; Fragoso, A. Chem. Rev. 2007, 107, 3088.

[5] Chen, H. Y.; Ji, H. B. AIChE. J. 2010, 56, 466.

[6] Zhan, H. Y.; Liu, H. Y.; Hu, J.; Jiang, H. F. Sci. China, Ser. B 2009 , 39, 253 (in Chinese).

(詹海莺, 刘海洋, 胡军, 江焕峰, 中国科学 B 辑: 化学, 2009, 39, 253.)

[7] Huang, J.; Ren, L. Y.; Fan, H. L.; Chen, Y. M. Sci. China, Ser. B 2011, 39, 301 (in Chinese).

(黄进, 任丽霞, 范红蕾, 陈永明, 中国科学 B 辑: 化学, 2009, 39, 301.)

[8] Breslow, R.; Zhang, X. J.; Xu, R.; Maletic, M.; Merger, R. J. Am. Chem. Soc. 1996, 118, 11678.

[9] Breslow, R.; Huang, Y.; Zhang, X. J.; Yang, J. Proc. Natl. Acad. Sci. U.S. A. 1997, 94, 11156.

[10] Yu, S. J.; Huang, X.; Miao, L.; Zhu, J. Y.; Yin, Y. Z.; Luo, Q.; Xu, J. Y.; Shen, J. C.; Liu, J. Q. Bioorg. Chem. 2010, 38, 159.

[11] Guo, Y. J.; Zhang, P.; Chao, J. B.; Shuang, S. M.; Dong, C. Spectrochim. Acta A 2008, 71, 946.

[12] Manka, J. S.; Lawrence, D. S. J. Am. Chem. Soc. 1990, 112, 2440.

[13] EL-Hachemi, Z.; Farrera, J. A.; Garcia-Ortega, H.; RamirezGutierrez, O.; Ribo, J. M. J. Porphyrins Phthalocyanines 2001, 5, 465.

[14] Mosinger, J.; Slavetinska, L.; Lang, K.; Coufal, P.; Kubat, P. Org. Biomol. Chem. 2009, 7, 3797.

[15] Hamai, S.; Koshiyama, T. Spectrochim. Acta A 2001, 57, 985.

[16] Kano, K. Colloid Polym. Sci. 2008, 286, 79.

[17] Guo, Y. J.; Guo, L.; Pan, J. H. Phys. Chem. Liq. 2007, 45, 261.

[18] Zhang, H. F.; Pan, J. H.; Gao, Y. L.; Guo, Y. J. Chin. J. Anal. Chem. 2006, 34, 1541 (in Chinese). (张红芬, 潘景浩, 高花玲, 郭玉晶, 分析化学, 2006, 34, 1541.)

[19] Schneider, H. J. Angew. Chem., Int. Ed. 2009, 48, 3924.

[20] Liu, J.; Xu, D. H.; Mei, W. J.; Pu, H. L.; Huang, J. W.; Ji, L. N. 
Chem. J. Chin. Univ. 2001, 22, 1446 (in Chinese).

(刘杰, 许东晖, 梅文杰, 蒲含林, 黄锦汪, 计亮年, 高等学校化 学学报, 2001, 22, 1446.)

[21] Hamai, S. J. Inclusion Phenom. Macrocyclic Chem. 2007, 58, 241.

[22] Qiu, W. G.; Li, Z. F.; Bai, G. M.; Meng, S. N.; Dai, H. X.; He, H. Spectrochim. Acta A 2007, 66, 1189.

[23] Kong, L. H.; Guo, Y. J.; Li, X. X.; Pan, J. H. Chin. J. Anal. Chem. 2007, 35, 537 (in Chinese).

(孔令宏, 郭玉晶, 李小香, 潘景浩, 分析化学, 2007, 35, 537.)

[24] Li, X. X.; Wang, J. W.; Guo, Y. J.; Kong, L. H.; Pan, J. H. J. Inclusion Phenom. Macrocyclic Chem. 2007, 58, 307.

[25] Li, X. X.; Guo, Y. J.; Wang, J. W.; Kong, L. H.; Pan, J. H. Supramol. Chem. 2008, 20, 243.

[26] Guo, Y. J.; Zhang, P.; Chao, J. B.; Shuang, S. M.; Dong, C. Spectrochim. Acta A 2008, 71, 946.

[27] Kong, L. H.; Guo, Y. J.; Li, X. X.; Pan, J. H. Spectrochim. Acta A 2007, 66, 594.

[28] Hu, Y.; Zhao, H. B.; Ning, J. H.; Ning, M. X.; Xu, Y. J.; Qiu, S. J.; Liao, J. X. Acta Chim. Sinica 2008, 66, 2391 (in Chinese).

(胡羽, 赵鸿斌, 宁静恒, 宁满霞, 徐勇军, 仇诗军, 廖俊旭, 化 学学报, 2008, 66, 2391.)

[29] Wang, W. L.; Zhao, H. B.; Ning, J. H.; Hu, Y.; Zhang, H.; Lu, X. J.; Ye, L. Y. Chin. J. Inorg. Chem. 2010, 26, 2025 (in Chinese). (王武林, 赵鸿斌, 宁静恒, 胡羽, 张辉, 陆旭甲, 叶领云, 无机 化学学报, 2010, 26, 2025.)

[30] Carofiglio, T.; Fornasler, R.; Lucchini, V.; Simonato, L.; Tonellato, U. J. Org. Chem. 2000, 65, 9013.

[31] Kano, K.; Nishiyabu, R.; Yamazaki, T.; Yamazaki, I. J. Am. Chem. Soc. 2003, 125, 10625.

[32] Sasaki, K.; Nakagawa, H.; Zhang, X. Y.; Sakurai, S.; Kano, K.; Kuroda, Y. Chem. Commun. 2004, 104, 408.

[33] Fathalla, M.; Neuberger, A.; Li, S. C.; Schmehl, R.; Diebold, U.; Jayawickramarajah, J. J. Am. Chem. Soc. 2010, 132, 9966.

[34] Yu, M.; Chen, Y.; Zhang, N.; Liu, Y. Org. Biomol. Chem. 2010, 8, 4148.

[35] Gu, Z. Y.; Guo, D. S.; Sun, M.; Liu, Y. J. Org. Chem. 2010, 75, 3600 .
[36] Yu, S. J.; Huang, X.; Miao, L.; Zhu, J. Y.; Yin, Y. Z.; Luo, Q.; Xu, J. Y.; Shen, J. C.; Liu, J. Q. Bioorg. Chem. 2010, 38, 159.

[37] Kiba, T.; Suzuki, H.; Hosokawa, K.; Kobayashi, H.; Baba, S.; Kakuchi, T.; Sato, S. J. Phys. Chem. B 2009, 113, 11560.

[38] Mazzaglia, A.; Valerio, A.; Micali, N.; Villari, V.; Quaglia, F.; Castriciano, M. A.; Scolaro, L. M.; Giuffrè, M.; Siracusano, G.; Sciortino, M. T. Chem. Commun. 2011, 47, 9140.

[39] Ribo, J. M.; Farrera, J. A.; Valero, M. L.; Virgili, A. Tetrahedron 1995, 51, 3705.

[40] Breslow, R.; Gabriele, B.; Yang, J. Tetrahedron Lett. 1998, 39, 2887.

[41] Yang, J.; Gabriele, B; Belvedere, S.; Huang, Y.; Breslow, R. J. Org. Chem. 2002, 67, 5057.

[42] Kuroda, Y.; Hiroshige, T.; Sera, T.; Shiroiwa, Y.; Tanaka, H.; Ogoshi, H. J. Am. Chem. Soc. 1989, 111, 1912.

[43] Kuroda, Y.; Hiroshige, T.; Sera, T.; Ogoshi, H. Carbohydr. Res. 1989, $192,347$.

[44] Kuroda, Y.; Sera, T.; Ogoshi, H. J. Am. Chem. Soc. 1991, 113, 2793.

[45] Weber, L.; Imiolczyk, I.; Haufe, G.; Rehorek, D.; Hennig, H. J. Chem. Soc., Chem. Commun. 1992, 301.

[46] French, R. R.; Holzer, P.; Leuenberger, M.; Nold, M. C.; Woggon, W. D. J. Inorg. Biochem. 2002, 88, 295.

[47] French, R. R.; Wirz, J.; Woggon, W. D. Helv. Chim. Acta 1998, 81, 1521.

[48] French, R. R.; Holzer, P.; Leuenberger, M. G.; Woggon W. D. Angew. Chem., Int. Ed. 2000, 39, 1267.

[49] Lee, J. B.; Hunt, J. A.; Grove, J. T. J. Am. Chem. Soc. 1998, 120, 7493.

[50] Li, Z. Y.; Li, J. F.; Li, C. Chin. J. Chem. 2002, 20, 399.

[51] Li, Z. Y.; Li, C.; Wu, X. Y.; Zhang, Y. N. Chin. Chem. Lett. 2000, $11,493$.

[52] Kralova, J.; Kejik, Z.; Briza, T.; Pouckova, P.; Kral, A.; Martasek, P.; Kral, V. J. Med. Chem. 2010, 53, 128.

[53] Chen, W. H.; Yan, J. M.; Tagashira, Y.; Yamaguchi, M.; Fujita, K. Tetrahedron Lett. 1999, 40, 891. 